\title{
Artigos
}

\section{Catalina Trebisacce}

Universidad de Buenos Aires

\section{Encuentros y desencuentros entre la militancia de izquierda y el feminismo en la Argentina}

\begin{abstract}
Resumen: Las reflexiones en torno a los encuentros y desencuentros entre la militancia de izquierda y el feminismo son de larga data y se actualizan periódicamente sin evidenciar ánimos de desgaste. En esta ocasión, se pretende dar tratamiento a algunos de los ribetes que ha presentado dicha relación en los años setenta, en Argentina, en el Partido Socialista de los Trabajadores. Esta década es especialmente interesante para el análisis puesto que, por un lado, fue un período que experimentó la irrupción de las llamadas nueva(s) izquierda(s) que marcaron la agenda política de los países occidentales. Por el otro, se trató de una década que vio emerger la segunda ola del feminismo, también de escala planetaria, con sus diferentes versiones geopolíticas.
\end{abstract}

Palabras claves: años 70; las nuevas izquierdas; feminismo; Partido Socialista de los Trabajadores (PST); Argentina.

Copyright (c) 2013 by Revista Estudos Feministas.

${ }^{1}$ El plural busca poner en relieve la ausencia de univocidad de aquellas experiencias. Las nuevas izquierdas compartieron ciertas características críticas respecto de las generaciones anteriores de militancia de izquierda, pero también desarrollaron otras características que las diferenciaron entre si.

2 En Argentina, la mayoría de las nuevas izquierdas desarrollaron propuestas de militancia armada que le daban la espalda al perimido teatro de la democracia $y$ política tradicional. Durante el período existieron en Argentina por lo menos 17 grupos armados, de los cuales 5 tuvieron alcance nacional.
Introducción: los años setenta, las nuevas izquierdas y las mujeres

Los años setenta conllevaron revoluciones y rebeliones en distintos órdenes de vida y de la política. Las expresiones políticas emergentes, bautizadas como la(s) nueva(s) izquierda(s), ${ }^{1}$ fueron el fenómeno dominante del período que tuvo lugar tanto en América Latina como en Europa o Estados Unidos, aunque con distintas características. Las nuevas generaciones de militantes de izquierda, desencantadas de los partidos de izquierda tradicionales, emprendieron un proceso de radicalización política que supuso ensayar arriesgados métodos en la práctica política, que implicaron, en muchos casos, la vía armada como estrategia necesaria para el cambio social. ${ }^{2}$

Asimismo, estas nuevas militancias avanzaron sobre dos puntos desatendidos por la militancia tradicional: el 
3 Para ilustrar este punto, Luis ORTOLANI, 2004/2005; Nahuel MORENO, 988; y también puede consultarse los estudios sobre el tema como el de Alejandra OBERTI, 2004/2005; Alejandra CIRIZA y Eva RODRÍGUEZ AGÜERO, 2004/2005; Vera CARNOVALE, 2008 , entre otros.

\footnotetext{
${ }^{4}$ En la primera mitad de los años setenta en Buenos Aires, Argentina, se gestaron varios pequeños grupos que se identificaban abiertamente con el feminismo, de los cuales los más destacados fueron la Unión Feminista Argentina UFA (1970-1976) y el Movimiento de Liberación Feminista MLF (19721976). Se trató experiencias feministas que reivindicaban su radical independencia respecto de agrupaciones políticas clásicas y de las de la nueva izquierda también. Para un estudio de estos grupos véase Alejandra VASALLO, 2005; Karin GRAMMÁTICO, 2005; Catalina TREBISACCE, 2010; y Catalina TREBISACCE y María Luz TORELLI, 2011.

${ }^{5}$ Paola MARTÍNEZ, 2009.

○ GRAMMÁTICO, 2011.
}

trabajo sobre la moral y las prácticas cotidianas de los/as militantes - que aquí referiremos como el campo de la subjetividad militante - y las mujeres. Para buena parte de las nuevas izquierdas, el trabajo sobre la subjetividad de los/ as militantes era considerado de crucial importancia para la producción de una verdadera revolución. La doctrina del Hombre Nuevo de Ernesto Guevara se dirigió en este sentido y fue ampliamente difundida. Ella suponía una revisión de las fronteras tradicionales entre la política y la vida privada. ${ }^{3}$

Pero es sobre el segundo punto, es decir, las mujeres, que versarán las indagaciones del presente trabajo. La nueva militancia contó en sus filas con una cantidad impensada de mujeres, una población habitualmente relegada al ámbito doméstico. Esta novedad debe leerse en sintonía con otras transformaciones que se experimentaron por aquellos años. Las décadas del sesenta y setenta significaron para las mujeres un proceso de transición y transformación. Muchas empezaron a trabajar en el mercado laboral y/o asistieron a las universidades, participando de experiencias que no fueron las de sus madres. Más allá de que luego muchas no lograran desarrollarse ni en el mercado laboral ni en las universidades como sus maridos o compañeros, el horizonte de expectativas de la población femenina había cambiado radicalmente. Estas transformaciones fueron materia de reflexión por parte de la sociedad, que consagró sus revistas de actualidad y los programas de televisión al tema; por parte los grupos feministas de aquellos años, que cuestionaron los alcances de dichos cambios; ${ }^{4}$ y por parte las organizaciones políticas, que se lanzaron a la formación de frentes o grupos femeninos.

Las experiencias de organización de la militancia femenina en las nuevas izquierdas en Argentina pueden agruparse en dos tipos. Por un lado, las desarrolladas por el Frente de Mujeres del Partido Revolucionario de los Trabajadores (PRT) y por la Agrupación Evita de Montoneros. Estos frentes han sido estudiados en profundidad por Paola Martíne ${ }^{5}$ y Karin Grammático, ${ }^{6}$ respectivamente. Los análisis de estas agrupaciones resultan coincidentes en varios puntos. En ambos casos fueron frentes creados por las direcciones de sus respectivas organizaciones con el fin de ampliar la base de militancia de cada agrupación (PRT y Montoneros) y politizar a las mujeres de los sectores más populares. Pero, como señalan las autoras, no fue parte de los objetivos - ni de las direcciones, primero, ni de los frentes, luego - el desarrollo de un trabajo político sobre la situación de opresión específica de las mujeres. Estas experiencias no sólo no tuvieron contacto con los grupos feministas locales o internacionales sino que rechazaron abiertamente al feminismo como movimiento político. Sin embargo, a pesar 


\begin{abstract}
${ }^{7}$ La lucha por la liberación de la mujer es uno de los nombres que por entonces adquiría la militancia feminista, hoy caído en desuso. Emplearé esta expresión a lo largo del texto porque entiendo que reproduce bien ciertos sentidos de la época en los que las palabras como 'feministas' o 'feminismo' eran empleadas con sumo cuidado.
\end{abstract}

${ }^{8}$ Avanzada Socialista fue el órgano de difusión partidaria del PST. En sus páginas tuvieron cita diversas reflexiones e informaciones referidas a la militancia partidaria, a la militancia sindical, a la militancia juvenil y a la militancia de las mujeres. La importancia y centralidad de esta publicación en la vida del partido y en la difusión de sus campañas y frentes de militancia motivó mi atención sobre ella.

9 Algunos de estos documentos internos forman parte de un archivo digital de la Revista de Teoría y Política Internacional Marxismo Vivo, dependiente del Instituto José Luís Rosa Sundermann, São Paulo, Brasil. Disponible en: https:// www.archivoleontrotsky.org/.

${ }^{10}$ EI PRT-La Verdad fue una escisión del PRT, partido característico de las nuevas izquierdas que consideraba necesario el desarrollo de la lucha armada para la transformación social. Las discusiones en torno al momento propicio para ello fueron los desencadenantes de la fractura. La agrupación que quedó dividida en, por un lado, el PRT-La Verdad, liderado por Nahuel Moreno, reacio a iniciar en ese momento una experiencia de guerrilla, y, por el otro, el PRT-EI Combatiente, que nucleaba a la fracción de liderada por Mario Roberto Santucho (quien sería luego el referente máximo del PRT) decidida a emprender la lucha guerrillera de forma inminente. Por su parte, el PSA Secretaría Coral representaba una de las tantas fracciones derivadas del viejo Partido Socialista, claramente alejado del horizonte guerrillero. Para la reconstrucción genealógica de las distintas vertientes del Partido Socialista, del que el PSA es una más, consultar María Cristina TORTII, 2005. de estos límites, las autoras encontraron que en dichos frentes femeninos las mujeres consiguieron politizar sus relaciones interpersonales y la desventajosa situación en la que se encontraban debido a la condición de su género. Martínez y Grammático insisten en señalar la importancia de recuperar las historias de estos frentes porque constituyeron un particular encuentro entre militancia de izquierda, militancia femenina y militancia feminista.

Por otro parte, se encuentran los casos del Partido Socialista de los Trabajadores (PST) y del Frente de Izquierda Popular (FIP), que aún no han sido estudiados en profundidad, y que desarrollaron otras experiencias en torno a la militancia de las mujeres. Dentro del PST se formó el grupo Muchacha y el FIP dio lugar al Movimiento Feminista Popular (MOFEP). A diferencia de los casos antes nombrados, estas agrupaciones contaron inicialmente con cierta autonomía respecto de las direcciones de sus partidos y ambos grupos femeninos estuvieron en contacto con los grupos feministas locales, con quienes compartieron las actividades de la agenda de militancia feminista local. Pero ni Muchacha y ni MOFEP fueron las únicas campañas desarrolladas por los partidos en torno a la lucha de las mujeres, por lo que representan casos privilegiados verdaderamente en los encuentros entre la militancia feminista, femenina y de izquierda.

El presente trabajo será una primera incursión a la experiencia del PST. Estudiaré la apuesta emprendida por este partido de dar tratamiento a 'la cuestión' de las mujeres mediante la iniciativa de desarrollar y participar en la lucha por la liberación de la mujer. ${ }^{7}$ Expondré los distintos ensayos llevados adelante por el partido con este fin, entre inicios de 1972 y fines 1975, de entre los cuales Muchacha ha sido sólo una versión. Buscaré evidenciar la convivencia de distintos sentidos en torno a las causas y los objetivos de la militancia feminista que tuvieron lugar al interior del partido y a lo largo de los años implicados. Trabajaré a partir del análisis del periódico semanal del partido (Avanzada Socialista) $)^{8}$ y de diversos documentos internos del partido producidos durante ese período. ${ }^{9}$

\section{El origen y las razones del Partido Socialista de los Trabajadores}

El Partido Socialista de los Trabajadores (PST) tuvo su nacimiento en los inicios de 1972 a partir de un acuerdo de fusión entre el Partido Revolucionario de los Trabajadores (PRT), fracción La Verdad, y el Partido Socialista Argentino (PSA), Secretaría Coral. Estos eran, sin embargo, dos partidos con historias muy distintas. ${ }^{10}$ 
1 Ernesto GONZALEZ, 2006.

12 Daniel CAMPIONE, 2008.

${ }_{13}$ Para ese entonces, la Argentina estaba nuevamente sumida en una dictadura militar que se había iniciado en 1966 derrocando al presidente constitucional Arturo Illia. Esta dictadura, autodenominada "Revolución Argentina", se mantuvo en el poder hasta las elecciones realizadas el 11 de marzo de 1973 en las que se impuso el peronismo con la fórmula Héctor J. Cámpora y Vicente Solano Lima. El peronismo es una fuerza política más numerosa de la historia argentina, nacida a mediados de la década del cuarenta con el liderazgo de Juan Domingo Perón y que desde 1955 había sufrido proscripción. Esto también brinda explicaciones respecto del descrédito en el que había caído, hasta 1973 al menos, el sistema representativo.

14 Resoluciones del C.C. del 20/ $02 / 72$, feb. 1972, p. 2. En el mismo documento el PRT-La Verdad explicaba su estrategia de hacer de esta fusión un canal para la tarea centralista legal del partido. Tarea que era comparada con la que desarrollaran las tendencias sindicales. Estas palabras nos advierten de un sopesado viro en la política del partido, en la que el plano de la llamada 'superficie' (por oposición a clandestinidad) adquirió, sin lugar a dudas, mayor centralidad. ${ }^{15}$ Para que sea más gentil a la lectura, me referiré a la fusión de los partidos, antes o después de la adquisición de la personería, como al PST.

${ }^{16}$ La relación del PST con el SWP se remonta a la historia del PRT-La Verdad en el marco del IX Congreso Mundial de la Cuarta Internacional (secretariado unificado) realizado en París en 1969. En este congreso se dividieron las aguas entre las izquierdas en torno al análisis de la realidad latinoamericana. Hubo agrupaciones de izquierdas que evaluaban que America Latina necesitaba profundizar la guerra de guerrillas mientras que otras izquierdas que consideraban que la situación era desfavorable para ello. En esta segunda posición se encontraron coincidiendo el SWP y
Como señalan Ernesto González"1 y Daniel Campione,${ }^{12}$ la conformación de este nuevo partido - el PST tuvo como finalidad la participación en la contienda electoral que se abrió tras la convocatoria lanzada en 1971 por el presidente de facto Alejando Agustín Lanusse, ${ }^{13}$ puesto que para poder participar de la misma el "Estatuto de Partidos Políticos" decretado por la dictadura militar vigente exigía altas cifras de afiliados, impensables para los dos partidos por separado.

En el caso del PRT-La Verdad, esta estrategia debió ser acompañada por una serie de revisiones más profundas ya que este partido había sido crítico de la vía parlamentaria. Sin embargo, desde fines de los sesenta había comenzado a caracterizar al período como el inicio de una etapa de democracia burguesa y de repliegue de las masas, para el cual el partido evaluaba como acción fundamental acompañar dicho repliegue y participar en la contienda electoral, para ampliar la propaganda del partido. Fue de esta manera que el PRT-La Verdad resolvió "aprobar el acuerdo celebrado con el PSA (Secretaría Coral) e ingresar masivamente al mismo partido". ${ }^{14}$ Durante todo el año de 1972, la difusión del partido se hizo bajo el nombre del PSA, mientras se realizaban los trámites necesarios para la adquisición de la personería para el PST, la que se consiguió hacia fines de $1972 .^{15}$

Es en esta coyuntura en la que se inscribieron las primeras expresiones en torno a la lucha por la liberación de la mujer, que fueron transformándose con los distintos escenarios políticos, como se verá a continuación.

\section{La lucha por la liberación de la mujer dentro del PST}

Numerosas pueden ser las razones que motorizaron dentro del PST la preocupación por la llamada liberación de las mujeres. Son razones que se vuelven huidizas al análisis, a consecuencia de la poca centralidad que dicha preocupación encontró en las fuentes documentales dejadas por el partido. De cualquier modo, pueden señalarse algunas causas posibles. En primer lugar, la emergencia en el mundo occidental del movimiento feminista de la segunda ola, que en estas geografías además de ser replicada por algunos grupos locales, fue retratada por las revistas de actualidad como un tema de interés de la población, que en el marco de una contienda electoral no debió ser un dato despreciable. En segundo lugar, puede señalarse la vinculación que el PST mantuvo con las nuevas izquierdas norteamericanas, más precisamente el Socialist Workers Party (SWP), quienes desarrollaron intensas experiencias de militancia feminista. ${ }^{16}$ 
el PRT-La Verdad, y a partir de este momento la relación entre estos dos partidos fue intensificándose con visitas y correos entre sus dirigentes.
17 1) AVANZADA SOCIALISTA, 8 marzo 1972; 2) AVANZADA SOCIALISTA, 15 marzo 1972; 3) AVANZADA SOCIALISTA, 22 marzo 1972 ; 4) AVANZADA SOCIALISTA, 26 abr. 1972; y 5) AVANZADA SOCIALISTA, 3 mayo 1972.

18 "Vemos hoy que, a pesar de que el capitalismo ha incorporado a la mujer al trabajo social, no ha roto la posición subordinada en que se encuentra. Por el contrario, la combinación de las viejas concepciones con las nuevas exigencias económicas, hace caer un nuevo peso sobre la mujer, que debe trabajar, sin verse por ello liberada del trabajo doméstico" (AVANZADA SOCIALISTA 15 marzo 1972, p. 10).
Ahora bien, en función del análisis de Avanzada Socialista, y más allá de las razones últimas de esta empresa del PST, es posible identificar un proceso dinámico, de marchas, contramarchas y caminos nuevos en su desarrollo. Desde las páginas del periódico y de las minutas internas del partido pueden distinguirse tres momentos. Cada momento refleja una conceptualización diferente de la militancia por la liberación de las mujeres, según la coyuntura y las relaciones de fuerza de las distintas posiciones frente a dicha militancia existentes dentro del partido. Expondré a continuación estos tres momentos.

\section{El reclamo de un lugar propio: los inicios}

El primer momento al que voy a referirme se inicia con la aparición de una nota en relación a la problemática de las mujeres en el segundo número de Avanzada Socialista, del 8 de marzo de 1972, y concluye con la última nota de aquel año en torno a esta temática que se produce dos meses después. Durante estos pocos meses Avanzada Socialista procuró dar un tratamiento casi semanal al tema de la lucha por la liberación de las mujeres, a la que destinaba una columna o media carilla en las páginas 10 - 12 de la publicación.

Las primeras notas estuvieron volcadas a retratar la situación de las mujeres, en un sentido amplio, general, no restringido a la problemática de la mujer comprometida en la lucha política, sindical o estudiantil. ${ }^{17}$ Eran notas que abordaron dos aspectos centralmente. Por un lado, se detenían en la situación de doble explotación que padecía la mujer en tanto que trabajadora y ama de casa, denunciando la invisibilización de esta última condición. ${ }^{18}$ Y por otro lado, los artículos analizaban el rol jugado por los medios de comunicación, la publicidad, la familia y la escuela en la producción de un esteriotipo de mujer, pasivo objeto del placer masculino.

Si bien las denuncias sobre la doble explotación eran esperables en tanto y en cuanto las herramientas teóricas del marxismo permitían dar cuenta de ella sin dificultad, llama la atención, sin embargo, encontrar una buena cantidad de reflexiones que abandonaron el materialismo clásico y pusieron sus ojos en las relaciones interpersonales, no inmediatamente económicas, y en la producción de la subjetividad femenina necesaria para garantizar la situación desfavorable de las mujeres.

En la familia comienza la educación para la sumisión de la mujer. Mientras la niña juega con la muñeca dentro del hogar, al varón se le proporcionan juegos creativos y sociales. La hija mujer debe participar en los 
${ }^{19}$ AVANZADA SOCIALISTA, 3 mayo 1972, sin paginación.

20 AVANZADA SOCIALISTA, 22 marzo 1972, sin paginación.

21 AVANZADA SOCIALISTA, 15 marzo 1972, p. 10.

${ }^{22}$ Cristina MOLINA PETIT, 2007. quehaceres domésticos [...] La adolescente no puede salir sola, se la controla y supervisa, al varón se le impulsa a salir, a divertirse. En la escuela se continúa la educación para la sumisión. La joven no puede tener una sana experiencia sexual ni siquiera una mínima información sobre el tema, pero la hipócrita burguesía usa todos los medios de comunicación para convertir a la mujer en un objeto sexual y obliga a muchas jóvenes a vender su cuerpo para poder comer. ${ }^{19}$

¿Quienes no quieren que nos ocupemos de política? Los mismo que manejan los medios de comunicación, hacen revistas para mujeres donde lo único que figura son modas, cocina y chismes artísticos; los que hacen publicidad y muestran a mujeres ante camisas blancas y pisos brillantes, pero nunca estudiando, investigando o realizando una labor social. Los mismos que están preocupados porque se les está moviendo el piso y temen que nuevos sectores pasen a la lucha. ${ }^{20}$

El propio capitalismo está interesado en mantener atrasadas a las mujeres, como reserva de mano de obra barata. La educación de las muchachas tiende a inculcarles que su objetivo en la vida debe ser el de cuidar al marido y a los hijos. La escuela, la familia, las revistas femeninas, compiten en crear en las mujeres jóvenes la mentalidad de esclavas pacientes del hombre. ${ }^{21}$

En esta última cita hay otro elemento importante. No sólo se denuncia a una fuerza opresiva productora de una subjetividad oprimida sino que también queda identificado un sujeto colectivo (los hombres), beneficiario de la explotación que padecían las mujeres. Y esta explotación era distinta de aquella que ejercía un explotador capitalista sobre un/a trabajador/a.

En este punto, el registro de las notas desplegadas en Avanzada Socialista estuvo en plena sintonía con los desarrollos teóricos de las feministas socialistas norteamericanas del SWP. Según Cristina Molina Petit, ${ }^{22}$ el feminismo socialista norteamericano de fines de los años sesenta se nutrió fuertemente del feminismo radical, que les permitió superar lo que sostiene la autora era la ceguera del marxismo en torno a la opresión de las mujeres. El feminismo radical identificaba a la opresión femenina como consecuencia de su sexo, de su condición de mujeres, y no como efecto de su situación respecto de las relaciones de producción, en las que también estaban inmersas. Molina Petit señala que este feminismo socialista identificó la existencia de un antagonismo de clases sexuales que no podía ser reducido al antagonismo de clases marxista. Este antagonismo sexual, conocido como patriarcado, desarrollaba sus propios modos de producción de la opresión. La autora 
${ }^{23}$ De todas maneras, es necesario aclarar que todas las veces que Avanzada Socialista alentó desde sus páginas la conformación de grupos de mujeres, se ocupó de señalar que desde el PST estaban convencidos/as que la liberación de las mujeres no podría ser total sin una liberación del pueblo entero del sistema de explotación capitalista. ${ }^{24}$ AVANZADA SOCIALISTA, 15
marzo 1972, p. 10.

${ }^{25}$ AVANZADA SOCIALISTA, 3 mayo 1972, sin paginación.

${ }^{26}$ Me refiero a los números 13 y 14 del mes de mayo, pero también al número 12 donde se anticipa más modestamente - la llegada de la candidata.

${ }^{27}$ El número del 24 de mayo tiene en su tapa el retrato de Jenness un el epígrafe al pie de la foto dice: "Luchadora feminista, primera mujer candidata a la presidencia de EEUU. Llegó a la argentina para impulsar el frente único antiimperialista y el polo socialista". señala que las feministas radicales denunciaban el trabajo doméstico no sólo en cuento a reproducción del capital sino también en tanto que esclavización de las mujeres por parte de sus propios maridos.

La aceptación, entonces, de la existencia de dos sistemas independientes de opresión, el capitalismo y el patriarcado, permitía al partido dar la bienvenida a organizaciones feministas que luchaban contra la opresión de las mujeres por fuera de las filas del partido. ${ }^{23}$ Desde las páginas de Avanzada Socialista se sostuvo que:

Nuestro partido entiende que la opresión de la mujer está tan íntimamente ligada a la división de la sociedad en clases, que sólo la eliminación del régimen capitalista y el advenimiento del socialismo podrá consolidar la definitiva emancipación femenina [...] Nuestro partido levanta un programa de liberación de la mujer que abarca todos los aspectos de la opresión, pero apoyará a todo grupo independiente que, aunque no coincida con nuestras posiciones, esté decidido a luchar por una situación más justa para la mujer. ${ }^{24}$

[...] estaremos en primera fila de las luchas de todas las jóvenes por sus reivindicaciones, apoyando la organización de movimientos amplios aunque no estén definidos por el socialismo. ${ }^{25}$

Asimismo, en esta primera sección que recorto quedan incluidos también tres números que cubrieron la visita de la candidata a presidenta norteamericana por el SWP, Linda Jenness, quien participó de distintos actos del PST. ${ }^{26}$ Jenness era representante de la lucha de clases en EEUU pero también abanderada de la lucha contra la guerra en Vietnam y una activa militante feminista.

Con la cobertura de su visita, las preocupaciones en torno a la lucha de las mujeres ocuparon la primera plana de Avanzada Socialista y, por primera vez, apareció en las hojas de la publicación la palabra 'feminismo'. ${ }^{27}$ Hasta ese momento, para designar a esta militancia la publicación había elegido, todas las veces, frases más largas, pero quizás menos urticantes, como: lucha por la liberación de las mujeres, o lucha de las mujeres, o mujeres en lucha. La llegada de Jenness permitió la visualización en primer plano de una militancia feminista que se practicaba dentro del partido y que se expresaba, haciendo síntoma de algún malestar, en las páginas traseras de la publicación. Al tiempo que, también, posibilitó la visualización de las tensiones que en torno a aquella militancia se suscitaban.

Por ejemplo, en la nota publicada bajo el título "Linda Jenness habla para Avanzada Socialista", quien realizó la entrevista a la candidata norteamericana formuló la siguiente pregunta: 
${ }^{28}$ AVANZADA SOCIALISTA, 24 mayo 1972 , p. 7.

\begin{abstract}
[Pregunta:] Un problema muy debatido dentro del movimiento revolucionario, es si se deben organizar movimientos feministas amplios, o si las mujeres deben luchar en sus respectivos lugares de trabajo, por las reivindicaciones comunes a sus sectores. Por ejemplo, la mayoría de los partidos de izquierda está en contra de que las mujeres se organicen independientemente porque dicen que eso no es revolucionario ¿Cómo responde Linda a está cuestión? [Respuesta de Linda Jenness:] Yo estoy de acuerdo con que hay opresión de acuerdo a la clase de que se trate. Pero, también digo que las mujeres negras, o las que sean, tenemos problemas comunes, y por eso tenemos que unirnos para luchar por esas reivindicaciones. Creo que hay ahora una necesidad acuciante de que las miles de mujeres dispuestas a luchar por cosas de mujeres se organices y lo hagan en común, así pertenezcan a ideologías distintas o no tengan ninguna. ${ }^{28}$
\end{abstract}

En la pregunta de la entrevistadora se devela la existencia de una tensión vivida en torno a la lucha de las mujeres y el sentido de aquella tensión: ¿La lucha de las mujeres debe/puede o no ser una lucha específica? Por la condición de duda que expresa la pregunta pareciera ser que entre la militancia de izquierda - y como no fue aclarado es posible pensar que dentro del PST también hubo quienes entendieron que lucha por la liberación de las mujeres debía/podía ser considerada con independencia de las otras luchas, mientras que estos/as militantes habrían estado poniendo en cuestión dicho punto.

En estos números, que trataron la visita de Jenness, también aparecieron fuertes referencias al grupo Muchacha (agrupación de mujeres del PST) que trabajaba en la lucha por la liberación de las mujeres y desarrollaba sus actividades con cierta autonomía respecto del partido. Desde el análisis de su publicación homónima, es posible sostener que en Muchacha el sentido de la lucha de las mujeres coincidía con el expresado en estos primeros números de Avanzada Socialista, ambos evidenciaban signos de un feminismo socialista radical, que interpretaba y denunciaba la opresión de las mujeres como un sistema de opresión independiente de otros. Aunque, a diferencia de lo que aconteció en la publicación del partido, en las páginas de Muchacha quedaron eternizadas (mediante la publicación de manifiestos y actividades) las vinculaciones que el grupo mantuvo con los grupos feministas locales e independientes en términos partidarios, como fueron la Unión Feminista Argentina (UFA) y el Movimiento de Liberación Feminista (MLF). Vinculación que no estuvo ausente de tensiones, como tampoco lo estuvo la relación que el grupo mantuvo con su propio partido. 
${ }^{29}$ AVANZADA SOCIALISTA, 31 mayo 1972 , p. 5.
El grupo Muchacha estuvo encargado de buena parte de la recepción de la candidata del SWP y de algunos actos específicos convocados en torno a la lucha de las mujeres. Y es en relación a esta tarea que Avanzada Socialista mencionó en varias ocasiones al grupo Muchacha. Lo interesante de aquellas menciones es que en todas las ocasiones Muchacha fue nombrado en tercera persona, como un grupo sin relación alguna con el partido. En una nota del 31 de mayo, haciendo referencia a un acto del que participó Jenness, Avanzada Socialista escribía:

El lunes pasado unas 1000 personas en su mayoría
mujeres, se reunieron para conocer la acción del
movimiento de liberación de la mujer en EEUU [...] La
conferencia fue organizada por el MLF y Muchacha,
dos grupos argentinos que, aunque con planteos
diferentes coincidieron en reivindicar a Linda Jenness
como una luchadora por los derechos de la mujer. ${ }^{29}$

Este no reconocimiento de los lazos de filiación se expresó también en las hojas de Muchacha en los que no se hizo nunca referencia al partido. Asimismo, otros hechos sugieren una relación poco resuelta entre el partido y el grupo, por ejemplo, Muchacha no contó con las instalaciones del partido para sus reuniones y la edición de su publicación, y debió depender del local de la UFA para desarrollar sus actividades.

Es posible pensar esta situación como parte del intento del PST de respetar la independencia de la militancia femenina, buscando asimismo evitar devenir un obstáculo para el acercamiento de quienes no se sintieran identificadas con el partido. Aunque también pudo ser parte de una estrategia para ampliar la base de militantes a partir de la incorporación de mujeres que pudieran acercarse a Muchacha y luego al partido, al tiempo que el partido se mantenía a resguardo, sin tener que afirmar su apoyo a una militancia sobre la que tenían, como se verá, más dudas que certezas.

Sin embargo, a pesar de los ribetes de la tensión partido-grupo, es interesante notar la insistencia con que el partido mantuvo la iniciativa de dar tratamiento a la militancia de las mujeres. Pues, incluso, meses después del regreso de Linda Jenness a Estados Unidos en el mes de mayo (momento en que Avanzada Socialista dejó de referirse a la lucha de liberación de las mujeres) Nahuel Moreno, uno de los más importantes referentes del partido, con miras al primer congreso del partido unificado, señaló como quinto punto de los catorce ejes esenciales de la futura campaña electoral: "[...] la igualdad entre la mujer y el hombre en el salario, las oportunidades y derechos. Guarderías infantiles las 24 horas 
${ }^{30}$ MORENO, 1972, p. 8.

31 Véase MARTINEZ, 2009; y GRAMMÁTICO, 2011.

${ }^{32}$ En principio desde fines de 1972 y casi todo el año 1973, el período estuvo signado por un clima de cierta primavera electoral. El 11 de marzo se llevaron adelante unas primeras elecciones presidenciales en las que volvió a participar la fuerza política más popular, el justicialismo, aunque no su líder (Juan Domingo Perón) que continuaba proscripto. El triunfo de esta fuerza fue esperable. Al regreso de Perón a la Argentina se repitieron las elecciones en septiembre con Perón como candidato, quien obtuvo un holgado triunfo. Este clima festivo de 1973 se fue enturbiando con los primeros meses de su mandato y ya para 1974, se produce un desembozado enfrentamiento entre sectores de peronismo de izquierda y el líder quien había decido orientar su política hacia los sectores de la derecha.

${ }^{33}$ La fórmula Coral-Ciapponi se consagró en diciembre de 1972 después de que el partido intentara infructuosamente convocar a militantes sindicales, como Agustín Tosco o José Francisco Páez, para compartir la fórmula electoral tanto en marzo como luego el septiembre. Sólo para septiembre consiguieron que Páez se presentara con Coral. del día totalmente gratuitos. Pensión igual a medio salario para cada hijo de madre soltera o separada".30

Habría que aclarar, sin embargo, que esta reivindicación por los derechos de la mujer apareció agrupada entre los siete puntos que desde una perspectiva marxista representaban reivindicaciones reformistas, es decir, que podían sostenerse sin conmover las bases de la sociedad de clases. Entre estos siete puntos Moreno estableció también las reivindicaciones relativas al reclamo por aumentos salariales, por ejemplo. Contrariamente, los restantes siete puntos sostenían reivindicaciones que implicaban un cuestionamiento al sistema capitalista, tales como la expropiación de los latifundios y su reparto. Estos últimos fueron resaltados en el documento con tipografía en mayúscula, lo que establece una clara jerarquía entre los catorce puntos mencionados, quedando en el grupo de los menos importantes la reivindicación por la igualdad de las mujeres.

De cualquier forma, la insistencia del PST a dar un lugar a la lucha por la liberación de la mujer debe ser subrayada, especialmente si se la considera en contraste con las experiencias que emprendieron otras agrupaciones de izquierda del período, como el PRT o Montoneros, quienes, como ya se dijo, impulsaron frentes femeninos explícitamente reacios a hablar de una lucha específica de las mujeres. ${ }^{31}$

\section{El relego del lugar proplo y el desarrollo de la campaña electoral}

El segundo período lo demarco entre mediados de 1972 hasta fines de 1974. Es un período de radicales cambios si se considera la política nacional. ${ }^{32}$ Sin embargo, o justamente por ello, el PST desde las páginas de Avanzada Socialista no mostró variaciones respecto de la militancia de las mujeres. En este largo período, la lucha por la liberación de las mujeres fue un asunto de escasísima importancia. De hecho, sólo en dos pequeñas notas se hace referencia a la "problemática de las mujeres" (y ya no a la lucha por la liberación de las mujeres, y menos aún a la militancia feminista). Las mismas aparecen vinculadas a las elecciones de marzo de 1973, elecciones en las que el PST participaba con una fórmula de género mixta: Juan Carlos Coral para presidente y Nora Ciapponi para vicepresidenta.

Es posible imaginar que el partido haya intentado replicar la experiencia norteamericana de llevar a una candidata mujer a la fórmula electora, después de haber fracasado en el intento de hacer participar a los dirigentes sindicalistas más combativos de entonces. ${ }^{33}$ Pues, por un lado, el PST, a pesar de la victoria de Richard Nixon, evaluó positivamente 
34 "El SWP sale de estas elecciones convertido - sin discusión - en el partido de izquierda más fuerte de los EEUU, en el gran partido que ha polarizado a la joven vanguardia yanqui, a los mejores activistas de las movilizaciones contra la guerra de Vietnam, por los derechos de los chicanos y los negros, por la liberación de la mujer. Avanzada Socialista saluda fervorosamente el triunfo del partido hermano" (AVANZADA SOCIALISTA, 1 nov. 1972).

${ }^{35}$ AVANZADA SOCIALISTA, 18 enero 1973; y AVANZADA SOCIALISTA, 22 feb. 1973.

${ }^{36}$ Decreto n. 659, de febrero de 1974. Para un análisis de este punto véase Karina FELITTI, 2006.

37 AVANZADA SOCIALISTA, 20-27 marzo 1974, p. 6; y AVANZADA SOCIALISTA, del 28 marzo al 5 abr. 1974 , p. 4.

${ }^{38}$ AVANZADA SOCIALISTA, 3 mayo 1974, p. 4. las elecciones norteamericanas respecto al crecimiento del SWP. ${ }^{34}$ Aunque, por otro lado también, probablemente la inclusión de una mujer en la fórmula pudo tener como aspiración dar representación a la población femenina que desde hace unos años pisaba con fuerza en el mundo público y político, como se ha explicado en la introducción.

En las dos únicas notas, que vinculadas a la candidatura de Ciapponi, hicieron referencia a la situación desfavorable de las mujeres, se desplegaron ligeras reflexiones sobre la doble explotación que padecían las mujeres y de las dificultades para militar en gremios, partidos y/o agrupaciones estudiantiles. ${ }^{35}$ No se produjo ninguna mención a una opresión específica que pueda pensarse con cierta independencia del sistema de opresión capitalista. Nora Ciapponi, quien no militaba ni en el grupo Muchachas ni entorno a las reivindicaciones de la lucha por la liberación de la mujer en aquellos años, fue sin embargo en este período, la referente de aquello que tuviera vinculación con dicha lucha.

Con excepción de estas notas, en este segundo período, no hubo mención alguna al tema de la desigualdad padecida por las mujeres, y nunca se mencionó la militancia específica de las mujeres. Y de hecho se produce cierta invisibilización de la problemática específica de las mujeres cuando en los primeros meses de 1974 Avanzada Socialista publicó dos notas muy discretas contra el decreto de prohibición de venta anticonceptivos lanzado por María Estela Martínez de Perón. ${ }^{36}$ En estas notas no se hizo mención de la campaña que en su contra mantenían los grupos feministas ( $y$ con ellos el grupo Muchacha) y menos aún se hico referencia a la lucha por los derechos de las mujeres. La lucha contra el decreto se afirmó en la libertad de elección de todo ser humano, hombre o mujer. ${ }^{37}$

Ahora bien, unos meses después, Avanzada Socialista sorprende con una solicitada del propio partido en la que se exponía una secuencia de puntos por los que los y las militantes del PST convocaban a la sociedad a luchar. En el punto nueve se lee:

Contra el decreto que prohíbe la venta de anticonceptivos. Por el derecho de la mujer a controlar su propio cuerpo y el de la familia a decidir qué número de hijos tener. Por la igualdad laboral, salarial y jurídica de las mujeres y los varones. Por el aborto legal y gratuito y la educación sexual. Por la instalación de guarderías gratuitas durante las 24 horas del día. ${ }^{38}$

Si consideramos documento interno elaborado por Moreno hacia fines de 1972 se ha producido una ligera despromoción de las reivindicaciones por los derechos de la mujer, que del quinto punto programático descendieron 
${ }^{39}$ PERIÓDICO, nOv. 1974, p. 1. EI informe remontaba los orígenes de la publicación al periódico $L a$ Verdad (del PRT) de unos 2.000 ejemplares en los tiempos de La verdad (1972) a unos 23.000 para 1974 con Avanzada Socialista.

\footnotetext{
${ }^{40} \mathrm{~A}$ consecuencia de las crecientes expresiones del feminismo internacional, las Naciones Unidas lanzaron en 1974 una campaña para declarar 1975 como el Año Internacional de la Mujer, sugiriendo a los gobiernos del mundo que tomaran medidas de beneficio para aquel sector de la población.
}

al noveno. Despromoción que coincide con la pérdida de cierta relevancia alcanzada por la lucha de las mujeres en las páginas de Avanzada Socialista. La publicación del partido, en este período electoral, habló (aunque bastante menos) de la situación problemática de las mujeres pero invisibilizó las luchas específicas y concretas de las mujeres, entre ellas al grupo Muchacha.

Las razones de este tratamiento están innegablemente vinculadas al contexto de contienda electoral. Podría pensarse que reivindicar la lucha de las mujeres resultara más riesgoso que la simple aceptación de la situación de opresión de las mujeres. Era posible hablar de su situación más no de los medios para combatirla, probablemente estos medios fueran también muy difusos y confusos para la mayoría de los/as militantes del PST.

\section{La clausura del lugar propio}

Finalmente, el tercer período que considero abarca desde fines de 1974 hasta fines de 1975. A mediados de diciembre de 1974 irrumpe en Avanzada Socialista una sección llamada "Mujer" que se mantuvo hasta fines de 1975. Esta innovación se inscribió en una serie de cambios que comenzaron a realizarse desde mediados de 1974, después de un informe realizado por el partido sobre su publicación, que arrojaba datos de un crecimiento sostenido y postulaba el desafío de ampliar aún más la cantidad de lectores, buscando "interesar a un público mucho más vasto que los militantes y activistas de fierro" ${ }^{39} \mathrm{~A}$ razón de este proyecto, se inauguraron distintas secciones y, entre ellas, estuvo la sección "Mujer".

Las primeras tres notas de la sección tuvieron un estilo muy similar a las primeras notas de comienzos de 1972. La primera de ellas, del 12 de diciembre, con la excusa de informar al respecto de los preparativos para las celebraciones por el declarado Año Internacional de la Mujer ${ }^{40}$ hacía abierta mención a la existencia de grupos feministas a quienes se les reconocía un interesante trabajo en la concientización de las mujeres aunque advertía también sobre ciertas exageraciones y excesos de los que eran parte.

Así es como en las últimas décadas han proliferado los movimientos feministas que, a pesar de sus excesos y exageraciones, en ciertos casos, han cumplido en general un papel muy útil. En un doble sentido: 1) porque estos movimientos han ayudado a que las mujeres tomen consciencia de su situación y luchen por modificarla; 2) porque objetivamente están atacando la opresión de la mujer, que es uno de los pilares que ayuda a sostener la propiedad privada y 
${ }^{41}$ AVANZADA SOCIALISTA, 12 dic. 1974, sin paginación.

${ }^{42}$ Trelew es una ciudad al sur de la república Argentina en la que se encuentra el penal de Rawson y era elegido por las fuerzas represivas para destinar a ciertos presos políticos con el fin de cortar cualquier contacto que pudieran mantener a pesar de la reclusión con el exterior. El 15 de agosto de 1972 un grupo de más de veinte detenidos/as pertenecientes al PRT-ERP, a las FAP (Fuerzas Armadas Revolucionarias) y a Montoneros intentaron una fuga. De ella sólo consiguieron alcanzar el avión con rumbo a Chile seis militantes. Los/ as restantes pactaron sus garantías pero el 22 de agosto fueron conducidos/as a un pelotón de fusilamiento en las instalaciones de la Base Naval Almirante Zar. A estos lamentables sucesos se los conoce como los fusilamientos de Trelew.

${ }^{43}$ Testimonio producido en unas Jornadas de homenaje a las feministas de los 70 en el año 2002. La desgrabación es gentileza de la antropóloga feminista argentina Mónica Tarducci. el régimen capitalista. Los movimientos feministas son tan útiles a la lucha de los trabajadores como lo son los de las naciones oprimidas, o los antiimperialistas de los países dependientes, o la lucha de los negros contra la discriminación. ${ }^{41}$

Cuando se habla de excesos de los grupos feministas locales, es difícil no pensar en las situaciones que atravesó la UFA un tiempo atrás, que provocaron finalmente la fractura del grupo en 1973. Haré una pequeña digresión al respecto.

Por aquellos años el proceso social de radicalización política impactaba incluso en las agrupaciones feministas que defendían la necesidad separar su lucha de las otras luchas. Las que siguen son anécdotas muy retomadas y que resonaron mucho entre las militantes de entonces. Una de ellas cuenta la triste coincidencia de plenario organizado por la UFA con los fusilamientos de Trelew en agosto de 1972. En este plenario habría habido feministas que se negaron a dar lugar en el debate a los acontecimientos ocurridos en la base naval del sur de la Argentina. ${ }^{42}$ La segunda recuerda cierta torpeza y banalización del golpe de estado efectuado al presidente de Chile Salvador Allende. Estas situaciones fueron precipitando la fractura de una de las agrupaciones, la UFA, que vio abandonar sus filas a quienes habían sido sus fundadoras y quienes habían sostenido con más firmeza la necesidad de "no politizar" al feminismo. Años después explicaba Leonor Calvera, una de las fundadoras, "La politización de los 70 era una de las cosas que hacía sumamente difícil seguir con la idea del feminismo como antes, que fue una de las razones por las que yo, María Luisa Bemberg, Gabriela Christeller y Alicia D'Amico nos retiramos de la UFA". ${ }^{43}$ Es completamente imaginable que todas estas situaciones fueran interpretadas como excesos del feminismo por parte de las militantes del PST.

Volviendo a la cita de Avanzada Socialista, ella contiene otro punto que es necesario subrayar. En esta nota se afirmó que la militancia feminista era también útil para la lucha que el partido estaba emprendiendo contra el capitalismo, de igual forma que lo eran las luchas de las poblaciones negras, por ejemplo. Puede decirse que las/os autoras/os de esta nota pugnaban por conseguir una definición de feminismo, que en algunos puntos se ligara a las experiencias que desarrollaban los grupos feministas radicales de Argentina y que, en otros puntos, no abandonara el compromiso con la lucha contra el capitalismo emprendida por el partido. Nuevamente, aparece un aspecto que cobra especial importancia si se considera que las organizaciones de izquierda destacadas del período denunciaban al 
${ }^{44}$ AVANZADA SOCIALISTA. Lucy de Ruiz no trabaja... es ama de casa. Argentina, año 3, n. 134, 30 dic. 1974. En ella se exponían dos cuadros en los que ponían el precio del mercado a las actividades realizadas por cada ama de casa, como ser: lavado y planchado, comida, etc., buscando graficar de qué manera todo este trabajo necesario para la reproducción de la fuerza de trabajo era en realidad impago.

45 AVANZADA SOCIALISTA. Qué hacer? reproducción de las reivindicaciones del PST. Argentina, año 3, n. 134, 30 dic. 1974, sin paginación.

${ }^{46}$ El Frente de Lucha por la Mujer tiene nacimiento después de que los grupos feministas fueran expulsados de los preparativos oficiales para el Año Internacional de la Mujer. De los preparativos participaron, sin embargo, comisiones femeninas de todo el arco político. Del Frente participó el grupo Muchacha también.

47 AVANZADA SOCIALISTA, 19 marzo 1975. feminismo como una expresión de la burguesía y no como una herramienta para la lucha contra el capital.

En estos números Avanzada Socialista no sólo recuperó las inquietantes palabras 'feministas' y 'grupos feministas' en la búsqueda de una definición propia, sino que llegó a publicar como ilustración de una nota que versaba sobre la doble jornada laboral de las mujeres, un volante muy conocido de la UFA en el que se retrataba a una mujer intentando cocinar, atender a sus tres hijos, contestar el teléfono y mantenerse sexy, por recomendación televisiva. ${ }^{44} \mathrm{Y}$ al pie de dicha nota, Avanzada Socialista reprodujo un punteo de los ejes programáticos sostenidos por el PST en torno a la lucha de las mujeres.

Surgen los puntos de nuestro programa:1) por guarderías; 2) por patria potestad compartida; 3) por divorcio absoluto; 4) por la derogación de la prohibición de venta de anticonceptivos; 5) por educación sexual científica; 6) por despenalización del aborto; 7) por pago a las amas de casa; 8) por igualdad salarial con los hombres. ${ }^{45}$

Las relaciones con el feminismo quedaban puestas sobre la mesa.

Sin embargo, las referencias explícitas o subliminales a la militancia específica feminista fueron desapareciendo en los siguientes números. La última nota en que el feminismo fue mencionado es del 19 de marzo de 1975. Es una nota crítica del accionar del Partido Comunista ante los preparativos para el acto por el Año Internacional de la Mujer.

El 6 de marzo de 1975 el PC realizó un acto en el marco de los preparativos del acto oficial, al que asistieron las militantes de Frente de Lucha por la Mujer ${ }^{46}$ que fueron abucheadas por la multitud cuando acercaron sus adhesiones. En esta nota se denunció al PC de no ofrecer a las mujeres un verdadero camino para su lucha, en tanto y en cuanto rechazaba la participación de mujeres organizadas por fuera de aquel partido. Asimismo, se lo acusó de subordinar la lucha de las mujeres a la práctica política de suma de afiliaciones. ${ }^{47}$ A las diferencias entre el PST y el tradicional PC venían a sumarse otras en relación a la lucha de las mujeres.

Ahora bien, después de esta nota del 19 de marzo, realizando una transformación vertiginosa, Avanzada Socialista cambió sustancialmente el perfil de su sección "Mujer". La sección comenzó a representar exclusivamente la realidad de las mujeres inscriptas en otras luchas, sindicales o estudiantiles. Ejemplo de ello son las notas al respecto de la participación de las mujeres y esposas en el reavivado conflicto de Villa Constitución, una localidad de la provincia de Santa Fe, crecida al amparo de la producción metalúr- 
${ }^{48}$ AVANZADA SOCIALISTA, 5 abr. 1975.

${ }^{49}$ AVANZADA SOCIALISTA, 5 jul. 1975. La trascendencia de esta huelga estuvo dada por ser la primera huelga general lanzada contra un gobierno peronista en toda la historia del peronismo.

${ }^{50}$ AVANZADA SOCIALISTA, 12 jul. 1975.

${ }^{51}$ AVANZADA SOCIALISTA, 1 agosto 1975.

${ }^{52}$ AVANZADA SOCIALISTA, 24 jul. 1975.

${ }^{53}$ AVANZADA SOCIALISTA, 21 nov. 1975; AVANZADA SOCIALISTA, 28 nov. 1975; AVANZADA SOCIALISTA, 5 dic. 1975; y AVANZADA SOCIALISTA, 19 dic. 1975.

${ }^{54}$ En medio de un duro conflicto con la Petroquímica Sudamericana (Hilandería Olmos), el 4 de setiembre de 1975, 5 jóvenes militantes del PST (corriente de la cual proviene el PTS y la mayoría de los grupos trotskistas de nuestro país) se dirigían a la fábrica a llevar lo recaudado para el fondo de huelga. Fueron interceptados y secuestrados. Aparecieron en la madrugada del 5 acribillados a balazos en el paraje La Balandra de Berisso. Tres compañeros que enterados de su secuestro salieron a denunciar el hecho, fueron secuestrados a metros del local central del PST en pleno centro de la ciudad de La Plata, y aparecieron horas después también fusilados. Este aberrante hecho pasó a la historia con el nombre de Masacre de La Plata.

${ }^{55}$ AVANZADA SOCIALISTA, 1 sept. 1975. gica, donde la seccional del poderoso sindicato Unión Obrera Metalúrgica se hallaba dirigida por una corriente antiburocrática integrada por activistas de izquierda y del peronismo combativo; ${ }^{48} \mathrm{O}$ las notas que refieren a la huelga general lanzada contra la severa política de ajuste conocida como el rodrigazo ${ }^{49}$ (en alusión al ministro de Economía de ese momento Celestino Rodrigo). Desde la sección "Mujer" se convocó entonces a las mujeres a participar de las jornadas de protesta y luego se retrató su participación en las movilizaciones de repudio. ${ }^{50}$ En otras ocasiones, incluso, la sección se convirtió en un llamado a las mujeres a participar de la lucha sindical. ${ }^{51}$

En algunos otros números, la sección procuró recoger testimonios de mujeres militantes de gremios o de agrupaciones estudiantiles que dieron cuenta de las dificultades que ellas tenían para emprender la militancia por su condición de mujer. En muchas ocasiones, las reflexiones sobre esta condición apareció en los últimos reglones, pudiendo el/la lector/a fácilmente adivinar que el objetivo central de la nota era conseguir un testimonio de un(a) militante del gremio de telecomunicaciones o del gremio del comercio y no, un testimonio que diera cuenta de las condiciones y la lucha específica de las mujeres. ${ }^{52}$

Finalmente, en los últimos meses, a partir de noviembre, la sección "Mujer" pasó a constituirse en un conjunto de informes históricos sobre las experiencias de militantes mujeres en otros lugares del mundo como Vietnam o China, ninguna de ellas abiertamente feminista o relacionada con una lucha específica a raíz de la condición de las mujeres. ${ }^{53}$

Curiosamente, a pesar de estas notables mutaciones que significaron el abandono de las referencias más explícitas a la específica militancia feminista, a partir de septiembre las notas comenzaron a ser membretadas con el símbolo del movimiento feminista (el símbolo del sexo femenino y dentro de él, una mano izquierda empuñada). Fueron los casos de las notas históricas pero también el de una nota de septiembre que recordaba a cuatro compañeras del PST asesinadas en la represión conocida como La Masacre de La Plata. ${ }^{54}$ Esta nota, que representaba simplemente la foto de cada compañera y un pequeño epígrafe en el que se exponían los datos de sus militancias, fue acompañada por el símbolo feminista aunque ninguna de ellas participó en el grupo de mujeres del PST. ${ }^{55} \mathrm{~A}$ partir de esta nota, todas las restantes de la sección fueron acompañadas por dicho símbolo.

La introducción de esta simbología explícita en el marco de notas, que no hablaban ni de experiencias de militancia feminista ni de problemáticas específicas de las mujeres, debe leerse como una nueva apuesta a redefinir el sentido de la lucha de las mujeres y de la lucha feminista. 
${ }^{56}$ Para un análisis detallado de la importancia que tomaron por entonces las revistas dirigidas al público femenino véase Isabella COSSE, 2007 y 2009.

${ }^{57}$ MINUTA..., feb. 1975, p. 3.
${ }^{58}$ Tanto El mundo de la mujer (1972) como Juguetes (1978) María Luisa Bemberg apunta contra los emprendimientos culturales que esclavizan a las mujeres desde la primera infancia y hasta la edad adulta a las mujeres, sin importan clase social alguna. Por otra parte, la revista Persona de María Elena Oddone dedica, en prácticamente todos los seis números de su primera época, notas referidas a la mujer y el mundo del consumo.
Nueva apuesta que queda develada al considerar los dos documentos internos del partido del período en torno a dicha militancia, el primero del mes de febrero y el segundo de julio de 1975.

Por un lado, en febrero, en simultaneidad con las primeras notas de este año que guardaban coincidencias con las notas de 1972, aparece un informe que lleva el título de "Minuta sobre la campaña de liberación de la mujer". Este documento no sólo recuperaba los antecedentes del movimiento feminista en el mundo y en Argentina, sino que le daba una inscripción particular, en diálogo conflictivo con las formaciones discursivas emanadas de las revistas femeninas y de actualidad que son productoras de una opresión específica de las mujeres, productoras de una subjetividad que las sujeta a la pasividad y la marginación. ${ }^{56}$

En un apartado que lleva el título Síntomas y situación actual se escribe:

Notamos síntomas de que el problema femenino se empieza a debatir a nivel casi doméstico. Si bien la proliferación de revistas femeninas estilo "Para ti" o "Vosotras" no es inferior a épocas anteriores han aparecido en el mercado masivo otras tales como "Ser Mujer", "Hombre y Mujer", "Pareja" donde el tema de la sexualidad femenina y las relaciones de pareja y con la sociedad la colocan fuera del papel de mojigata y ama de casa perfecta [...] A esto hay que agregarle la aparición de "Persona", la primer revista feminista del país y que es leída aproximadamente por 2.500 personas en la ciudad de Buenos Aires. ${ }^{57}$

La referencia a revistas de moda y actualidad no representaban un dato menor por dos razones. En principio, porque las expresiones políticas más radicalizadas tendieron a considerar a estos emprendimientos culturales como manifestaciones triviales de la ideología capitalista, a los que no les cabía otra actitud que la indeferencia o el rechazo. En segundo lugar, porque los grupos feministas locales sí se ocuparon de estos emprendimientos a quienes dirigían sus más ácidas críticas. Puede consultarse los cortometrajes de María Luisa Bemberg (militante de la UFA) o los seis números de la revista Persona del MLF. ${ }^{58}$

Renglones más abajo, la minuta describe detalladamente las características y las diferencias de los dos grupos feministas existentes (UFA y MLF), y enumera las actividades compartidas.

Los dos grupos feministas existentes: Movimiento de Liberación de la Mujer y Unión Feminista Argentina ya han sido conocidos por el partido. Hemos realizado campañas conjuntas cuando vino Linda Jenness y por la campaña contra la ley que prohíbe el uso de 
${ }^{59}$ MINUTA..., feb. 1975, p. 5.

${ }^{60}$ MINUTA..., feb. 1975, p. 5-6.

${ }^{61}$ INFORME..., 18 jul. 1975.

${ }^{62}$ MINUTA..., 18 jul. 1975, p. 3. anticonceptivos. Si bien son grupos ultraminoritarios tienen el mérito de ser los primeros del país. ${ }^{59}$

Es interesante de destacar la valoración positiva que los/as redactores de la minuta hacen de las experiencias feministas a pesar de su carácter ultraminoritario.

Debemos comprender ante todo que el hecho de que las mujeres se organicen es de por sí un síntoma positivo aunque en sus reuniones no discutan de política [...] [Nuestro] trabajo tiene como objetivo máximo movilizar (al nivel que sea posible) a las mujeres, por sus problemas comunes, sin hacer diferencias de clase ni políticas. No es una táctica para captar. ${ }^{60}$

Y nuevamente aparecen los signos de la afirmación de la militancia feminista con independencia de otro tipo de militancia.

Pero para julio de ese mismo año, y acompañando el radical cambio de perfil de la sección "Mujer" de Avanzada Socialista, la segunda minuta practicó apreciaciones muy distintas en torno al modo de llevar adelante la lucha de las mujeres.

En julio de este año el PST, que había mantenido una lectura cauta sobre las condiciones para el desarrollo de la revolución o de la lucha armada, cambia su caracterización del período a partir de una serie de revueltas que sacudieron por entonces al país. En un informe sindical de este mes se afirmaba estar en una situación pre revolucionaria. ${ }^{61}$ Es en este contexto de agitación en el que se inscribió el segundo documento sobre la lucha de las mujeres. Este documento llevó de título Minuta sobre el trabajo de la mujer. En él se afirmaba:

el partido está tratando de realizar una experiencia casi inédita en los últimos años: los movimientos feministas de la década del 60-70 surgieron fundamentalmente en los países imperialistas en momentos en que la lucha de clases era escasa, de modo que ellos se desarrollaron en forma independiente de las luchas sindicales. En nuestro país la situación es absolutamente la contraria y por lo tanto estamos tratando de desarrollar un trabajo sobre las mujeres donde se plantean problemas nuevos tales como: ¿cómo ligar la participación de las mujeres a las luchas sindicales? ${ }^{62}$

Aparecía aquí una preocupación (cómo las mujeres participarán en las luchas sindicales) que ni asomaba en la primera minuta de febrero de este mismo año. Y más abajo, en esta segunda minuta, se enfatizaba un alejamiento respecto de las demás ideas sostenidas en la de febrero.

Por el momento, y no sabemos por cuanto tiempo o si será una característica permanente, no hay prácti- 
${ }^{63}$ MINUTA..., 18 jul. 1975, p. 5-6.

${ }^{64}$ MINUTA..., 18 jul. 1975, p. 9. camente ninguna posibilidad de un movimiento de liberación de la mujer con carácter independiente. Esto no significa que ignoremos nosotros en nuestra actividad los problemas específicos de las mujeres, lo que queremos decir es que se manifestarán y se manifiestan alrededor y muy combinados con los problemas sindicales y políticos de nuestro país. [...] algo debemos tener claro: por las característica, tradición y peso del movimiento obrero en nuestro país, el trabajo de la mujer pasa esencialmente alrededor de la lucha de clases, en forma combinada y no como movimiento paralelo e independiente. ${ }^{63}$

Finalmente, para terminar con la redefinición del sentido de la lucha de las mujeres, este documento afirmaba que los puntos programáticos que tiempo antes se habían levantado para la lucha femenina habrían perdido fuerza entre las militantes.

Actualmente se estaba realizando desde el periódico y desde el Frente un programa de 809 puntos. Pero vemos que ninguno de ellos es absolutamente sentido por el conjunto de las mujeres [...] no vemos todavía que ninguno de ellos sea el eje nucleador. Es probable que durante un largo tiempo el eje de nuestro trabajo [...] sea el de participación de la mujer. ${ }^{64}$

Es decir, se abandonaron las reivindicaciones por el trabajo doméstico, las guarderías, el aborto, las pastillas, etc. y se tomó como eje central de la lucha de las mujeres, el incentivo a la participación de las mujeres en otros frentes de lucha, como el partidario, el sindical y el estudiantil. Decisión que encontró su correlato en la sección "Mujer" que, como ya mencioné, desde mayo de 1975 estuvo orientada a retratar mujeres militantes de otros frentes (sindicales y estudiantiles) y a incentivar a otras mujeres a sumarse y participar de luchas no específicamente feministas.

\section{Tres observaciones a modo de conclusión}

El estudio de la experiencia del PST en torno a la militancia feminista ha pretendido ser la recuperación de una versión otra (otra más, otra nueva) de los encuentros y desencuentros entre la militancia de izquierda y la militancia feminista en los tempranos años setenta. Del análisis de este caso surgen algunas reflexiones.

En principio, debería decirse que la experiencia del PST en torno a la militancia feminista ha sido de carácter múltiple y dinámica, que ella ha variado al interior del partido y a lo largo de los años. En este sentido, ha sido interesante constatar la disposición a los ensayos, los aciertos y los fracasos, que dicho partido ha tenido en torno a la militancia 
${ }^{65}$ MINUTA..., abr. 1975, p. 3.

${ }^{66}$ Pues los intentos del PST de participar y dar lugar a la lucha para la liberación de las mujeres no se detuvieron en 1975 sino que fueron retomados con mayor intensidad hacia fines de la década de los setenta (consecuencia un clima político más favorable) por medio de la publicación de la revista Todas. feminista. En abril de 1975, en una minuta sobre Avanzada Socialista, se reconocía y celebraba esta actitud

implícita o explícitamente el CC [Comité Central] y la DN [Dirección Nacional] votaron en este período las siguientes campañas, Misiones, democrática, Salario y Convenio, frente único obrero, populismo, juventud, Mujer, intelectuales, Portugal y Vietnam. [...] Con mujer e intelectuales, AS [Avanzada Socialista] tiene la política de estar abierto a las pruebas y experimentos de estos frentes, aún no estructurados, por lo que publica artículos aún no compartiéndolos. ${ }^{65}$

La visibilización de estos ensayos ha permitido contemplar la disposición a la innovación política dentro del partido. Sin embargo, el derrotero de los acontecimientos políticos pareciera haber trazado un camino y fortalecido ciertas perspectivas de la militancia de las mujeres por sobre otras. En nuestro primer período, un contexto político preelectoral, Avanzada Socialista ponía el acento en la militancia por la liberación de la mujer, mientras que en el segundo período, en plena campaña electoral, las menciones a aquella militancia pasaron a ser reemplazadas por la simple enunciación y denuncia de los problemas de las mujeres. Evidentemente el consenso del partido, en dicha coyuntura, no alcanzaba para reivindicar una militancia de aquel estilo aunque sí podía reconocerse la situación de opresión que padecían las mujeres. Finalmente, en el tercer período, en el contexto político de creciente radicalización política (recordemos que en este período, ya fuertemente marcado por un clima represivo, vivió una pequeña primavera de revueltas y huelgas que tensionaban el estado de cosas), el PST tanto en la páginas de Avanzada Socialista como en sus minutas internas, expresó un abandono incluso de la denuncia de la situación de las mujeres para comenzar a hablar otra vez de una militancia femenina pero en un sentido bien distinto al primero, completamente dependiente de la línea de militancia del partido. En este tercer momento, los problemas específicos dejaron de ser mencionados y la lucha por la liberación pasó a ser reemplazada por la participación de las mujeres en los distintos frentes sindicales, estudiantiles, etc. del partido.

De cualquier forma, no deja de ser interesante evidenciar que la búsqueda por participar de la militancia femenina, y en ocasiones, feminista, no cesó ni durante todos estos períodos ni incluso después. ${ }^{66}$

En segundo lugar, he comprobado que la consideración de la militancia feminista con independencia de la lucha contra el capitalismo fue uno de los nudos gordianos en los que el partido, sus dirigentes y sus distintos grupos de mujeres se vieron enredados/as y comprometidos/as. En este nudo 
uno de los extremos enredados estuvo vinculado a los postulados del feminismo radical, que pisaba con fuerza en las agrupaciones feministas locales. Así es que, en ciertas ocasiones, tuvo lugar una consideración del feminismo que entendía la opresión de las mujeres como específica, es decir, independiente de la opresión del sistema capitalista. Se entendía que esta opresión se producía con cierta autonomía de las condiciones materiales de existencia de aquellas mujeres y se consolidaba fundamentalmente a partir de poderes inmateriales, que trabajaban en la producción de subjetividades femeninas que garantizaban las pautas culturales de opresión de las mujeres. En otros momentos, el feminismo fue considerado parte subsidiaria de la lucha socialista por la liberación del pueblo. Y finalmente, en otras ocasiones, se reconoció abiertamente un desinterés por la lucha específica de las mujeres y se buscó canalizar la participación de ellas en la militancia partidaria, sindical o estudiantil. Todas estas versiones, incluida esta última, fueron intentos de dar un sentido propio a la militancia feminista por parte del partido.

La consideración de los ribetes de este nudo gordiano es interesante porque no sólo se anudó y se resolvió de otras maneras en otras agrupaciones del período (como fueron los casos del FIP, del PRT y de Montoneros), sino porque es un problema que continúa insistiendo y retornando como núcleo de preocupaciones y tensiones en buena parte de los movimientos sociales contemporáneos.

\section{Referencias}

ARGENTINA. Decreto n. 659, de febrero de 1974. Argentina, 1974.

AVANZADA SOCIALISTA. Mujer: explotación por partida doble. Argentina, año 1, n. 2, 8 marzo 1972, sin paginación. 1972, p. 10.

. Mujeres en lucha. Argentina, año 1, n. 3, 15 marzo

. Mujeres en lucha: "no, a mí no me interesa la política".

Argentina, año 1, n. 4, 22 marzo 1972, sin paginación.

. Las mujeres del GAN. Argentina, año 1, n. 9, 26 abr.

1972, sin paginación.

. Antes nos vendaban los pies, ahora nos lavan el cerebro. Argentina, año 1, n. 10, 3 mayo 1972, sin paginación.

. Linda Jenness habla para Avanzada Socialista.

Argentina, año 1, n. 13, 24 mayo 1972, p. 7.

. La liberación femenina y la moral burguesa. Argentina, año 1, n. 14, 31 mayo 1972, p. 5.

. Nixon ganó pero el socialismo también. Argentina,

año 1, n. 36, 1 nov. 1972, sin paginación. 
. Nora Ciapponi habla de la mujer. Argentina, año 1, n. 45, 18 enero 1973, sin paginación.

. Nora Ciapponi defiende a la mujer. Argentina, año

1, n. 50, 22 feb. 1973, sin paginación.

. Más hijos ¿Quién los alimenta? No al decreto contra los anticonceptivos. Argentina, año 2, n. 96, 20-27 marzo 1974, p. 6.

. "La ley de los anticonceptivos en una medida más de tipo represivo" nos dijo Cipe Linkovsky. Argentina, año 2, n. 97, del 28 marzo al 5 abr. 1974, p. 4.

. Nuestro partido lo invita a luchar por estos puntos.

Argentina, año 3, n. 102, 3 mayo 1974, p. 4.

. 1975 Año Internacional de la Mujer. Argentina, año

3, n. 132, 12 dic. 1974, sin paginación.

. Lucy de Ruiz no trabaja... es ama de casa. Argentina, año 3, n. 134, 30 dic. 1974, sin paginación.

. Qué hacer? reproducción de las reivindicaciones

del PST. Argentina, año 3, n. 134, 30 dic. 1974, sin paginación. . ¿Qué le ofrece a las mujeres el Partido Comunista? Argentina, año 4, n. 139, 19 marzo 1975.

. Así participamos en las luchas obreras. "Mujeres

son las nuestras...". Argentina, año 4, n. 141, 5 abr. 1975. . Las mujeres con la CGT. Argentina, año 4, n. 152, 5 jul. 1975, sin paginación.

. Lucha contra el "Plan Rodrigo" ¿cómo participaron las mujeres? Argentina, año 4, n. 153, 12 jul. 1975, sin paginación.

. Conversando con una compañeras del gremio de comercio. Argentina, año 4, n. 155, 24 jul. 1975, sin paginación.

. Elecciones sindicales. Incorporemos mujeres a las listas, levantemos un programa para la mujer. Argentina, año 4, n. 156, 1 agosto 1975, sin paginación.

. Nuestras primeras mártires. Argentina, año 4, n. 162, 1 sept. 1975, sin paginación.

. La mujer en el mundo. Vietnam. Argentina, año 4, n.

172, 21 nov. 1975, sin paginación.

. La mujer en el mundo. Vietnam. Continuación.

Argentina, año 4, n. 173, 28 nov. 1975, sin paginación.

. La mujer en el mundo. China. Argentina, año 4, n.

174, 5 dic. 1975, sin paginación.

. La mujer en el mundo, China. Argentina, año 4, n.

176, 19 dic. 1975, sin paginación.

CAMPIONE, Daniel. "La izquierda no armada en los años setenta tres casos, 1973-1976". In: LIDA, Clara; CRESPO, Horacio; YANKELEVICH, Pablo (Comp.). Argentina, 1976: estudios en torno al golpe de Estado. Buenos Aires: Fondo de Cultura Económica, 2008. v. 1. p. 154-168. 
CARNOVALE, Vera. "Moral y disciplinamiento interno en el PRT-ERP". Nuevo Mundo Nuevos Mundos, Debates, p. 213, 2008. Disponible en: <http://nuevomundo.revues.org/ 38782 >. Acceso en: 4 jul. 2013.

CIRIZA, Alejandra; RODRÍGUEZ AGÜERO, Eva: "Militancia, política y subjetividad: la moral del PRT-ERP". Políticas de la Memorias, Buenos Aires, n. 5, p. 85-92, 2004/2005.

COSSE, Isabella. "Cultura y sexualidad en la Argentina de los sesenta: usos y resignificaciones de la experiencia transnacional". Estudios Interdisciplinarios de América Latina y el Caribe, 2007. Disponible en: <http://www1.tau. ac.il/eial/index2.php?option $=$ com_content\&do_pdf $=1 \&$ $\mathrm{id}=70>$. Acceso en: 10 mayo 2012.

. "Los nuevos prototipos femeninos en los años 60 y 70: de la mujer doméstica a la joven 'liberada'". In: ANDÚJAR, Andrea et al. De minifaldas, militancias $y$ revoluciones: exploraciones sobre los 70 en la Argentina. Buenos Aires: Luxemburgo, 2009. p. 171-186.

FELITTI, Karina. "En defensa de la libertad sexual: discursos y acciones de feministas y homosexuales en los '70". Revista del CEHIM, año 2, n. 2, 2006. sin paginación.

GONZALEZ, Ernesto (Coord.). El trotskismo obrero e internacionalista en la Argentina. EL PRT La Verdad ante el Cordobazo y el clasismo (1969-1971). Buenos Aires: Fundación Pluma, 2006. Tomo 4. v. 1.

GRAMMÁTICO, Karin: “Las 'mujeres políticas' y las feministas en los tempranos setenta: ¿un diálogo (im)posible?". In: ANDÚJAR, Andrea et al. Historia, género y política en los 70. 2005. Disponible en: <http//www.feminaria.com.ar/ colecciones/temascontemporaneos $>$. Acceso en: 12 mayo 2012.

. Mujeres montoneras: una historia de la Agrupación Evita 1973-1974. Buenos Aires: Ediciones Luxemburg, 2011.

INFORME de atividades. Documento Interno, jul. 1973.

INFORME sindical: vivimos una situación de crisis pre revolucionaria. Documento Interno, 18 jul. 1975.

MARTíNEZ, Paola. Género, política y revolución en los años setenta: las mujeres del PRT-ERP. Buenos Aires: Imago Mundi, 2009.

MINUTA sobre la campaña de liberación de la mujer. Documento Interno, feb. 1975.

MINUTA sobre el periódico. Documento Interno, abr. 1975.

MINUTA sobre el trabajo de la mujer. Documento Interno, 18 jul. 1975.

MOLINA PETIT, Cristina. "El feminismo socialista estadounidense desde la 'nueva izquierda': las teorías del sistema dual (capitalismo+patriarcado)". In: AMORÓs, Celia; DE MIGUEL, Ana. Teoría feminista: de la Ilustración a la 
globalización. Del feminismo liberal a la posmodernidad. Madrid: Minerva, 2007. p. 147-187.

MORENO, Nahuel. Nuestra campaña electoral. Documento Interno, dic. 1972.

. La moral y la actividad revolucionaria. Bogotá: Editorial

Perspectiva, 1988. Disponible en: <http://www.marxists.org/ espanol/moreno/obras/07_nm.htm>. Acceso en: 10 mayo 2012.

OBERTI, Alejandra. "La moral según los revolucionarios". Políticas de la Memoria, Buenos Aires, n. 5, p. 77-84, 2004/2005.

ORTOLANI, Luis. "Moral y proletarización". Políticas de la Memoria, Buenos Aires, n. 5, p. 93-102, 2004/2005.

PERIÓDICO. Documento Interno, segundo congreso ordinario, nov. 1974.

RESOLUCIONES del C.C. del 20/02/72. Documento Interno, feb. 1972.

TORTTI, María Cristina. "Las divisiones del Partido Socialista y los orígenes de la nueva izquierda argentina". In: CAMARERO, Hernán; HERRERA, Carlos Miguel (Ed.). EI Partido Socialista en Argentina: sociedad, política e ideas a través de un siglo. Buenos Aires: Prometeo, 2005, p. 391-412.

TREBISACCE, Catalina. "Una segunda lectura sobre las feministas de los '70 en Argentina". Conflicto Social, Revista del Programa de Investigaciones sobre Conflicto Social, Instituto de Investigaciones Gino Germani, Facultad de Ciencias Sociales, UBA, año 3, n. 4, p. 2652, dic. 2010.

TREBISACCE, Catalina; TORELLI, María Luz. "Memorias feministas, ni escritas ni contadas, guardadas: metiendo las narices en el archivo personal de una feminista argentina de los años setenta". Kula, Antropólogos del Atlántico Sur, Revista de Antropología y Ciencias Sociales, n. 4, p. 76-94, abr. 2011.

VASSALLO, Alejandra. “'Las mujeres dicen basta': movilización, política y orígenes del feminismo argentino en los'70". In: ANDÚJAR, Andrea et al. Historia, género y política en los 70. 2005. Disponible en: <http//www.feminaria.com.ar/ colecciones/temascontemporaneos $>$. Acceso en: 14 mayo 2012.

[Recebido em 20 de fevereiro de 2012 ,

reapresentado em 28 de maio de 2012 e aceito para publicação em 30 de maio de 2012] 
Agreements and Disagreements Amongst Left Militancy and Feminism in Argentina Abstract: The agreements and disagreements amongst left militancy and feminism bring longstanding reflections that are periodically updated with no evidence of intended weakening. In this occasion, there's the will of treating some particular aspects given in this relationship during the Seventies, in Argentina in the Worker's Socialist Party. This decade is especially interesting to analyze since on one hand, it was a period in which the so-called new left(s) burst in, marking the political agenda of western countries and, on the other hand, it was a decade that witnessed the emergence of the second wave of feminism, also on a world wide base, with its different geopolitical versions.

Key Words: The Seventies; New Lefts; Feminism; Worker's Socialist Party; Argentina. 